Purdue University Purdue e-Pubs

2012

\title{
Theoretical and Experimental Analysis of the Superheating in Heat Pump Compressors
}

Jose Nilton Fonseca

jfonseca@embraco.com.br

Rodrigo Kremer

Thiago Dutra

Follow this and additional works at: https://docs.lib.purdue.edu/icec

Fonseca, Jose Nilton; Kremer, Rodrigo; and Dutra, Thiago, "Theoretical and Experimental Analysis of the Superheating in Heat Pump Compressors" (2012). International Compressor Engineering Conference. Paper 2140.

https://docs.lib.purdue.edu/icec/2140

This document has been made available through Purdue e-Pubs, a service of the Purdue University Libraries. Please contact epubs@purdue.edu for additional information.

Complete proceedings may be acquired in print and on CD-ROM directly from the Ray W. Herrick Laboratories at https://engineering.purdue.edu/ Herrick/Events/orderlit.html 
1568 , Page 1

\title{
Theoretical and Experimental Analysis of the Superheating in Heat Pump Compressors
}

\author{
Jose N. FONSECA ${ }^{1}$, Rodrigo KREMER ${ }^{1}$, Thiago DUTRA ${ }^{2}$ \\ ${ }^{1}$ EMBRACO, Research \& Development Group, \\ Joinville, Santa Catarina, Brazil \\ Jose_Fonseca@embraco.com.br \\ Rodrigo_kremer@embraco.com.br \\ ${ }^{2}$ Department of Mechanical Engineering, Federal University of Santa Catarina \\ Florianópolis, SC, Brazil \\ dutra@polo.ufsc.br \\ * Corresponding Author
}

\begin{abstract}
In a conventional cooling system, refrigerant superheating inside the compressor is largely responsible for overall energy losses, increasing the compression specific work and decreasing the cooling capacity. In heat pump applications, superheating not only affects the compression loss, but also the specific heating capacity of the system, since the inlet temperature of the condenser depends on the final temperature of compression. Kremer et al. (2011) proposed a new approach to identify and understand the superheating losses in compressors submitted to heat pump applications. In this paper, a more accurate approach is proposed and the effects of refrigerant superheating are analyzed using a compressor thermal model. Different configurations of compressors are experimentally and numerically evaluated in order to validate the theoretical model. The obtained results follow the trend established by the theoretical purpose.
\end{abstract}

\section{INTRODUCTION}

The heating systems grounded on the vapor compression principle have become more and more attractive due to its higher efficiency levels. Thus, the demand for high efficiency heat pumps has increased significantly and motivates researches to continually develop this type of systems.

The compressor is one of the most studied components of a heat pump system. Horn (1976) identified some characteristics of the compressor that impacts the heat pump systems performance. Several critical issues were pointed out, such as: liquid handling, external oil circulation, high mean load of bearings and operating time.

Squarer et al. (1976) mentioned the necessity of redesigning reciprocating compressors for heat pump applications, especially for low evaporating temperatures. The authors presented a numerical analysis, comparing the reference compressor with a modified one. Among all modifications suggested, the suction gas insulation seemed to be the main source of performance gain (5\% to 15\%), under low back pressure (LBP) conditions.

Giuffrida (1984) presented a compressor-condenser concept as a high efficiency solution for heat pump applications. The layout guarantees the compressor cooling by the water flow inside the heat-exchanger. According to the author, it is possible to obtain an improvement between $10 \%$ and $15 \%$ on the heating COP due to the discharge heat recovery and superheating reduction.

It is well known that, for household refrigeration compressors, a significant portion of the energy losses is associated with refrigerant superheating before (i.e., along the suction gas path inside the compressor) and during the vapor 
compression process (Possamai \& Todescat, 2004). Such a useless superheating provides a reduction of the refrigerant mass flow rate, and an increase of the specific compression work (Gosney, 1982).

Kremer et al. (2011) analyzed the relationship between the compressor superheating and the system performance as the compressor is submitted to heat pump and refrigeration applications. In addition, a new approach to identify the superheating losses in the heat pump system was suggested. Therefore, part of this study will be presented here and a more accurate approach will be proposed.

Figure 1 illustrates the decrease of $C O P$ as a function of the initial compression temperature for a single stage $\left(7.2^{\circ} \mathrm{C} / 54.4^{\circ} \mathrm{C}\right)$ refrigeration system operating with R-134a. The COP, Capacity and Power Consumption were calculated considering a refrigeration cycle with: a) isentropic compression in a specified initial temperature; b) No pressure drop and no subcooling at the condenser; c) Isenthalpic expansion; d) No pressure drop and outlet temperature equal to $20^{\circ} \mathrm{C}$ in the evaporator. The $C O P$ is normalized with respect to the $C O P$ of a reference cycle in which the initial compression temperature is $20^{\circ} \mathrm{C}$. In other words, the reference cycle presents no superheating inside the compressor, until the refrigerant is compressed. It is also observed that the compression power remains almost constant and the refrigerating capacity decrease as the useless superheating is varied.

It is clear that useless suction gas superheating provides a compressor performance decrease for a refrigeration system. However, regarding to heat pump applications, such a performance behavior is not the same. To ensure this statement, the following analysis is proposed: consider a compressor with a fixed loss in bearings and electrical motor. Figure 2 shows the $C O P$ and the heating capacity when that loss is not used to increase the initial compression temperature $\left(20^{\circ} \mathrm{C}\right)$ and when this loss is $100 \%$ used to increase the initial temperature $\left(40^{\circ} \mathrm{C}\right)$. The COP and the capacity were normalized with respect to the $C O P$ and capacity of a cycle in which the initial compression temperature is $20^{\circ} \mathrm{C}$ and there are no losses in bearings and electrical motor. This is the ideal situation $\left(C O P / C O P_{c y c l e}=1\right)$ and when the loss is considered, $C O P / C O P_{c y c l e}$ is lower than 1 . On the other hand, if this loss is used to superheat the refrigerant gas upstream the compression, the $C O P$ increases, but it does not reach the reference cycle $C O P$ level (i.e. without losses). Hence, it is reasonable to drag out some benefit of the unavoided compressor losses.

Moreover, when the suction gas superheating is provided by the discharge system heat, the heat pump performance is affected in a different manner. Figure 3 presents the COP decrease as a function of the initial compression temperature, similarly with the refrigeration case. In this situation, the suction gas superheating is given at the expense of the heating capacity. In addition, there is also a reduction of the mass flow rate. Therefore, the heating capacity decreases as the initial compression temperature increases.

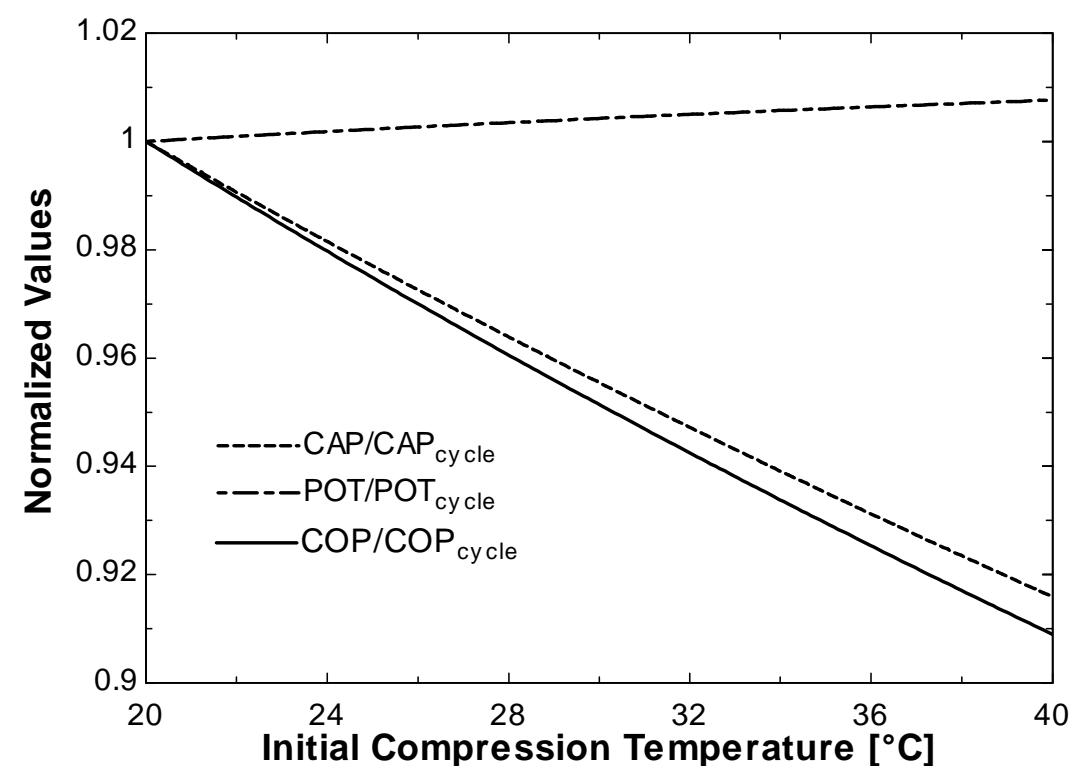

Figure 1: Effect of superheating on COP, capacity and power (refrigeration application) 
1568, Page 3

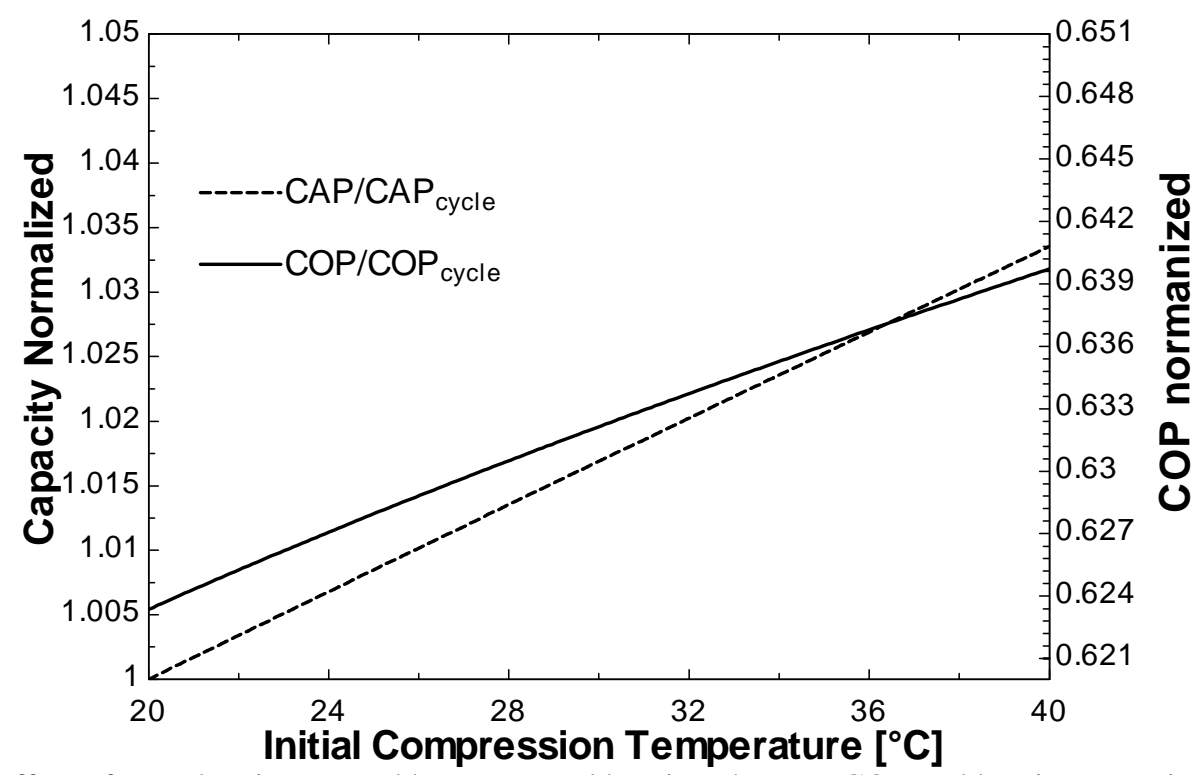

Figure 2: Effect of superheating caused by motor and bearings heat on COP and heating capacity (heat pump application)

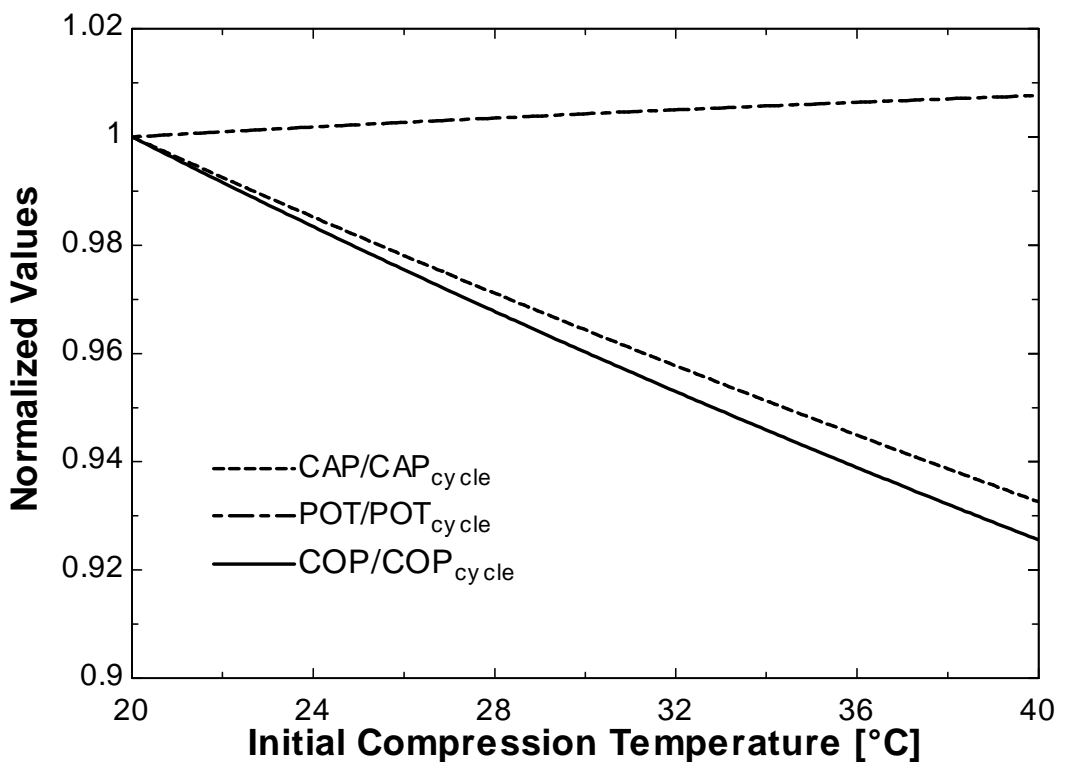

Figure 3: Effect of superheating caused by discharge heat transfer on COP, heating capacity and power (heat pump application)

The current analysis is intended to show that the refrigerant gas superheating along the suction path may be beneficial or harmful to the compressor performance, depending on the heat source. Thus, for heat pump applications, it is not possible to assess the superheating loss only by evaluating the cylinder inlet temperature.

\section{THEORETICAL DEVELOPMENT}

A traditional way of analyzing the compressor performance is dividing the energy losses in an inventory of losses. Thus, the effects of several solutions can be seen and, bottlenecks become easily identifiable. From an energetic point of view, the power consumption supplied to the electrical motor is converted into electrical losses and mechanical power. The last one is delivered to the compressor shaft and part of this energy is dissipated by bearings 
and compression mechanism. The remaining energy is converted into thermodynamic energy, which is used to provide the mass flow of the refrigerant gas and elevation of its pressure inside the compression chamber. There are several losses involved in this thermodynamic compression process, such as pumping losses (regarded to valves and muffler losses), suction gas superheating and leakage. Nevertheless, only the superheating of the refrigerant gas is considered. Indeed, the present paper deals with to approach the superheating losses impact on compressor performance for heat pump applications. The superheating losses can be estimated by:

$$
\dot{W}_{s h}=\dot{W}_{s}-\dot{W}_{s, s h}
$$

where the $\dot{W}_{s, s h}, \dot{W}_{s}$ are isentropic compression powers which take and do not take into account the suction gas superheating, respectively. Both terms are referenced to the capacity computed from the superheating situation.

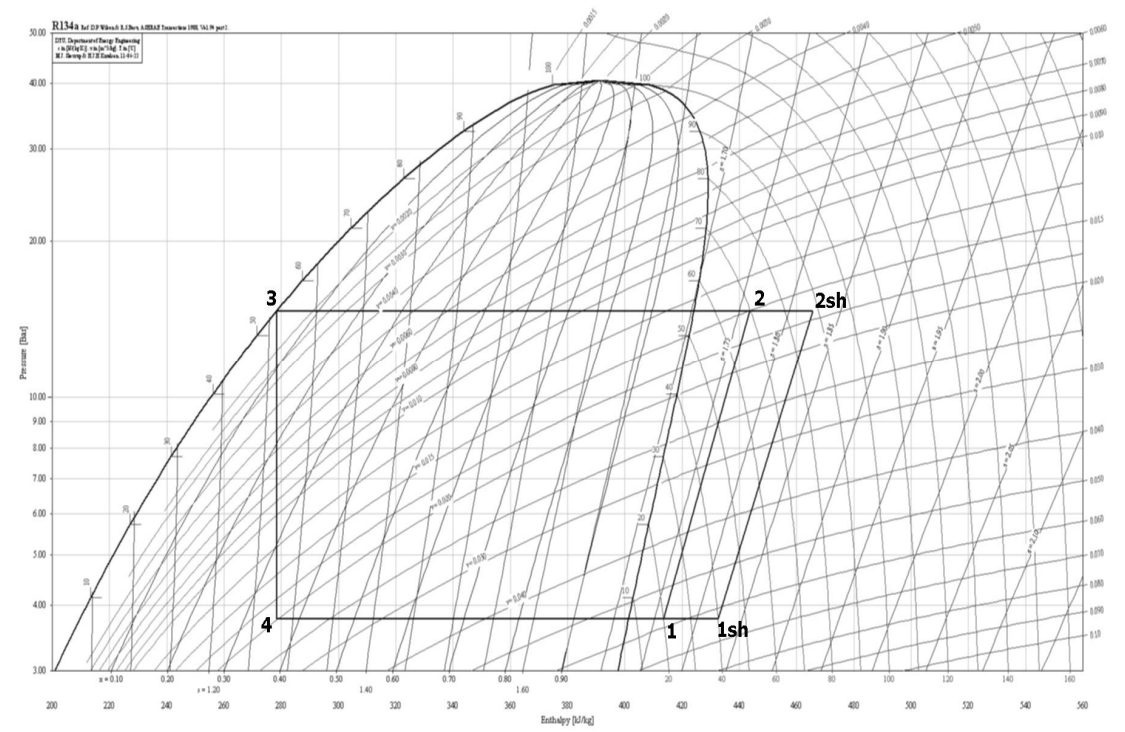

Figure 4: Representative P-h diagram for heat pump/refrigeration application (Klein, 2010)

\subsection{Effect of the Superheating on Compressors for Cooling}

For refrigeration systems, $\dot{W}_{s}$ can be calculated using the ideal coefficient of performance. Hence, eq. (1) becomes:

$$
\dot{W}_{s h, \text { cooling }}=\frac{\dot{m}_{s h}\left(h_{\mathbf{1}}-h_{\mathbf{3}}\right)}{C O P_{s, \text { cooling }}}-\dot{m}_{s h}\left(h_{\mathbf{2}, s, s h}-h_{\mathbf{1}, s h}\right)
$$

and,

$$
C O P_{s, \text { cooling }}=\frac{\left(h_{1}-h_{3}\right)}{\left(h_{2, s}-h_{1}\right)}
$$

then,

$$
\dot{W}_{\text {sh,cooling }}=\dot{m}_{s h}\left(h_{\mathbf{2}, s}-h_{\mathbf{1}}\right)-\dot{m}_{s h}\left(h_{\mathbf{2}, s, s h}-h_{\mathbf{1}, s h}\right)
$$

Physical properties are calculated from Lemmon et al. (2002). Regarding to heat pump applications, eq. (4) is unable to provide the superheating impact on the heat pump performance, because it only considers the compression power variation. In these cases, the superheating also affects the specific heating capacity. 
1568, Page 5

\subsection{Effect of the Superheating on Compressors for Heating}

Since superheating modifies the compression final temperature, the discharge line temperature is altered and, therefore, the specific heating capacity of a heat pump system. Due to that, thermal management solutions may affect the specific heating capacity. In this way, it is very important to identify the superheating losses correctly.

For heat pump systems, $\dot{W}_{s}$ can be calculated using the ideal coefficient of performance, similarly to the refrigeration application. Thus, eq. (1) is rewritten as:

$$
\dot{W}_{\text {sh,heating }}=\frac{\dot{m}_{s h}\left(h_{\text {out }}-h_{\mathbf{3}}\right)}{C O P_{s, \text { heating }}}-\dot{m}_{s h}\left(h_{\mathbf{2}, s, s h}-h_{\mathbf{1}, s h}\right)
$$

and,

$$
C O P_{s, \text { heating }}=\frac{\left(h_{\mathbf{2}, s}-h_{\mathbf{3}}\right)}{\left(h_{\mathbf{2}, s}-h_{\mathbf{1}}\right)}
$$

then, eq. (1) becomes:

$$
\dot{W}_{\text {sh,cooling }}=\frac{\dot{m}_{s h}\left(h_{\mathbf{2}, s}-h_{\mathbf{1}}\right) \cdot\left(h_{\text {out }}-h_{\mathbf{3}}\right)}{\left(h_{\mathbf{2}, s}-h_{\mathbf{3}}\right)}-\dot{m}_{s h}\left(h_{\mathbf{2}, s, s h}-h_{\mathbf{1}, s h}\right)
$$

Comparing eq. (4) and eq. (7), one notices that the first term of the right hand side of eq. (7) presents a term to assess the superheating impact on the specific heating capacity.

\section{RESULTS AND DISCUSSIONS}

A $60 \mathrm{~Hz}$ reciprocating compressor operating with R134a was selected for the analysis. The compressor was submitted to an operating condition, represented by a pair of evaporation and condensation temperatures, $7.2^{\circ} \mathrm{C} / 54.4^{\circ} \mathrm{C}$. The tests were conducted in a calorimeter facility following refrigerating conditions established by standards, with environment and compressor inlet temperatures controlled. Typical uncertainty values are about $\pm 2{ }^{\circ} \mathrm{C}$ for temperature and $\pm 2 \%$ for mass flow rate and electrical power measurements. Further details of the experimental facility can be found in Dutra (2008).

By default, the selected compressor operates according to the indirect suction concept, which consists in a nonalignment of the compressor inlet tube with the muffler inlet. Due to this configuration, the refrigerant gas is forced to flow into the compressor cavity (where motor, discharge system and bearings are placed) before entering the suction muffler. Further this standard configuration, two additional ones were purposed to provide the superheating assessment: i. semi-direct suction, where the suction tube is aligned with the muffler inlet, and ii. insulation of the compressor body combined with the semi-direct suction concept.

A computational program was employed to simulate the operation of the selected compressor, aiming to obtain its thermal profile and performance parameters. Such a program consists on a coupling between thermal and thermodynamic models and is based on an integral formulation (Lumped Parameter Methodology), firstly presented by Todescat et al. (1992). The thermal model was calibrated for the semi-direct suction configuration by adjusting the global thermal conductance between components. To simulate the indirect suction configuration, the thermal conductance of the suction muffler was considered as being 10 times higher than the semi-direct configuration. Furthermore, the shell was set up as ideally insulated to simulate the insulated compressor with semi-direct suction situation.

Table 1 shows the thermal profile most important points. The temperatures for the indirect suction compressor had a good agreement comparing to the experimental results. On the other hand, the numerical result for the insulated case predicts higher temperature levels because the shell was considered ideally insulated and this is a very difficult condition to be experimentally achieved. 
Comparing the three configurations, one notices that the lowest muffler outlet temperature is found at the semidirect suction configuration. Additionally, the numerical simulations compute the initial compression temperature. Actually, such a temperature is the one which better represents the suction superheating level, because the suction process is ended inside the compression chamber as the suction valve closes. The semi-direct suction configuration presents the lowest value of initial compression temperature, as observed for the muffler outlet temperature. Indeed, this result is expected, since the refrigerant gas enters the compressor and is directly driven to the muffler inlet. Such a lower temperature provides the highest mass flow rate among the three configurations of the numerical result, as Fig. 5 shows.

In a typical refrigeration analysis, the cooling capacity depends only on the mass flow rate, which gives the highest value in the semi-direct suction. However, regarding to heat pump systems, the heating capacity depends also on the compressor discharge temperature. Therefore, as Fig. 5 depicts, the highest heating capacity level is observed at the insulated compressor combined with semi-direct suction configuration.

Error! Reference source not found. and Error! Reference source not found. show the performance parameter results obtained by experiment and numerical simulation, respectively. Both methodologies indicate that the highest $C O P_{\text {heating }}$ level is found at the semi-direct + insulated configuration. On the other hand, the highest $C O P_{\text {cooling }}$ was noticed at the semi-direct suction configuration. These results reflect the importance of the criteria employed to select a compressor to be adopted in a heat pump application. Since a compressor is the best to be used in a refrigeration system is not a guarantee that it is also the best choice for an equivalent heat pump application.

Table 1: Thermal Profile, in C.

\begin{tabular}{lcccccc}
\hline \multirow{2}{*}{\multicolumn{1}{c}{ Temperatures }} & \multicolumn{2}{c}{ Indirect Suction } & \multicolumn{2}{c}{ Semi-direct Suction } & \multicolumn{2}{c}{ Insulated Compressor } \\
\cline { 2 - 6 } & Exp. & Num. & Exp. & Num. & Exp. & Num. \\
\hline Compressor Inlet & 35.0 & 35.0 & 34.9 & 35.0 & 35.0 & 35.0 \\
Muffler Outlet & 68.5 & 68.6 & 51.9 & 51.9 & 59.2 & 68.1 \\
Initial Compression - T1_sh & --- & 78.6 & --- & 62.8 & --- & 78.8 \\
Cylinder & 89.8 & 96.8 & 86.1 & 86.1 & 93.1 & 102.4 \\
Discharge Chamber & 124.1 & 126.6 & 112.3 & 112.3 & 119.9 & 128.2 \\
Compressor Discharge & 99.6 & 102.8 & 96.2 & 96.2 & 104.8 & 114.4 \\
Electrical Motor & 69.9 & 78.5 & 86.5 & 86.5 & 102.8 & 110.8 \\
Shell & 44.8 & 44.0 & 47.2 & 47.2 & 77.1 & 85.2 \\
\hline
\end{tabular}

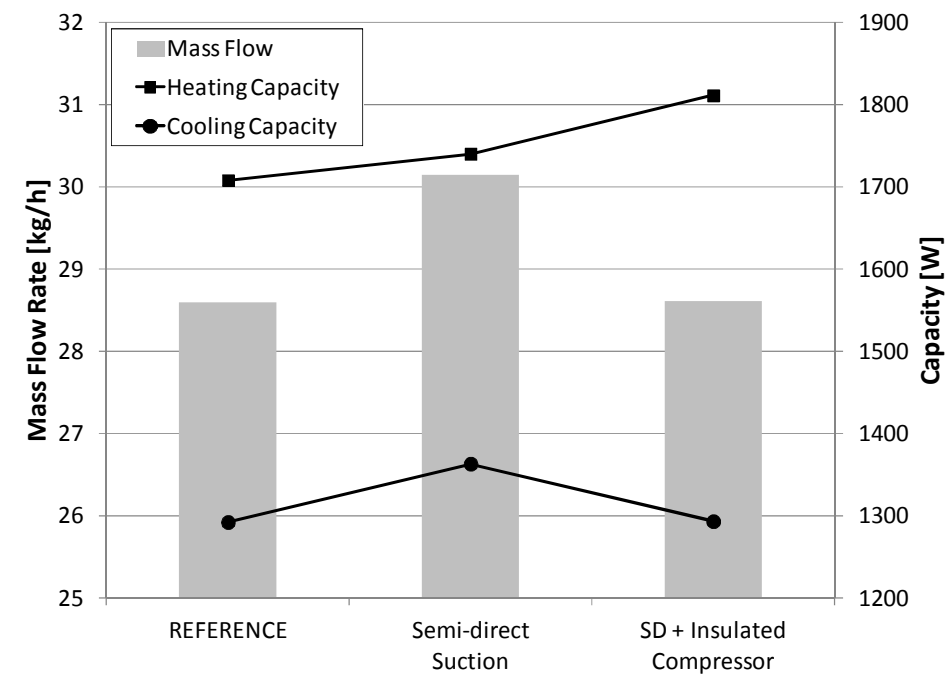

Figure 5: Mass Flow vs Capacity - Numerical results 
Still regarding Error! Reference source not found., one observes that superheating losses behave differently in refrigeration and heat pump applications, as already noticed in COP. In cooling, the lowest superheating loss is found at the semi-direct suction configuration, which means that this is the best configuration in terms of superheating. Indeed, the $C O P_{\text {cooling }}$ outcome agreed with that. In heating, the lowest superheating loss is indicated in the semi direct + insulated configuration. This parameter also agreed with the $C O P_{\text {heating }}$ result. It should be mentioned that the negative value attributed to the superheating loss is due to a measurement difficulty: temperature measurement inside the compression chamber. As already commented, the suction process ends as the suction valve closes and the gas is superheated inside the compression chamber until the compression process start. Hence, the initial compression temperature should be used rather than the muffler outlet one to calculate $h_{l}$ in eq. (6). Tab. 3 shows that no negative superheating losses are found, because the initial compression temperature is assessed in numerical simulations.

Finally, numerical and experimental results showed the same trends. The compressor insulation combined with a semi-direct suction was found to be the best configuration to heat pump. The most probable explanation for that is that the compressor insulation hindered the heat release through the shell, which increased the amount of heat absorbed by the suction system. In this situation, the compressor insulation brought an improvement of the performance because the superheating was provided in majority by bearings and electrical motor losses.

Table 2: Performance parameters - experimental results

\begin{tabular}{lccc}
\hline & REFERENCE & $\begin{array}{c}\text { Semi-direct } \\
\text { Suction }\end{array}$ & $\begin{array}{c}\text { SD + Insulated } \\
\text { Compressor }\end{array}$ \\
\hline Heating Capacity [W] & 1576 & 1608 & 1689 \\
Cooling Capacity [W] & 1212 & 1259 & 1265 \\
COP/COP ref $_{\text {heating }}$ & 1.000 & 1.006 & 1.019 \\
COP/COP ref Cooling & 1.000 & 1.025 & 0.993 \\
c & 0.69 & 0.65 & 0.77 \\
\hline Superheating Loss - Cooling [W] & 35.3 & 18.9 & 26.9 \\
Superheating Loss - Heating [W] & 15.1 & 2.7 & -1.6 \\
Pumping Loss [W] & 106.2 & 106.5 & 118.2 \\
Bearing Losses [W] & 15 & 15 & 15 \\
Electric Motor Loss [W] & 95 & 91 & 94 \\
\hline
\end{tabular}

Table 3: Performance parameters - numerical results

\begin{tabular}{lccc}
\hline & REFERENCE & $\begin{array}{c}\text { Semi-direct } \\
\text { Suction }\end{array}$ & $\begin{array}{c}\text { SD + Insulated } \\
\text { Compressor }\end{array}$ \\
\hline Heating Capacity [W] & 1708 & 1740 & 1811 \\
Cooling Capacity [W] & 1292 & 1363 & 1293 \\
COP/COP ref heating & 1.000 & 1.011 & 1.061 \\
COP/COP ref cooling & 1.000 & 1.047 & 1.002 \\
c & 0.78 & 0.70 & 0.97 \\
\hline Superheating Loss - Cooling [W] & 48.5 & 33.2 & 48.7 \\
Superheating Loss - Heating [W] & 22.2 & 15.7 & 5.6 \\
Pumping Loss [W] & 105.8 & 108.8 & 105.8 \\
Bearing Losses [W] & 15 & 15 & 15 \\
Electric Motor Loss [W] & 102.9 & 102.0 & 99.2 \\
\hline
\end{tabular}

\section{CONCLUSIONS}

The present work presented a theoretical analysis of the superheating effect in a reciprocating compressor adopted for a heat pump application. Experimental and numerical results supported the analysis with good agreement. 


\section{8 , Page 8}

In the theoretical analysis, it was proposed a different way to treat the suction gas superheating when the compressor is employed in heating systems. The superheating losses impact the power consumption and also heating capacity.

The effects related in the theoretical analysis were also noticed in the experimental and numerical tests, where the results showed a COP improvement as the compressor was insulated and the suction gas superheating was increased. It is important to emphasize that $C O P$ gain is possible only when the heat sources are bearings, electrical motor or any other, except the discharge line.

The agreement between theoretical and experimental results brings a clear evidence of the importance of how to address the superheating issue in heat pump applications. It was also noticed the importance of using the $C O P_{\text {heating }}$ as a criterion to select a compressor for this application, instead of only analyzing the $\mathrm{COP}_{\text {cooling }}$.

\section{NOMENCLATURE}

$\begin{array}{lll}C O P & \text { coefficient of performance } & (-) \\ h & \text { specific enthalpy } & (\mathrm{J} / \mathrm{kg}) \\ \dot{m} & \text { mass flow rate } & (\mathrm{kg} / \mathrm{s}) \\ \dot{W} & \text { power } & (\mathrm{W})\end{array}$

\begin{tabular}{ll}
\multicolumn{2}{c}{ Subscripts } \\
cooling & $\begin{array}{l}\text { refrigeration } \\
\text { system }\end{array}$ \\
heating & heat pump \\
& system \\
out & discharge line \\
$s$ & isentropic \\
sh & superheating
\end{tabular}

\section{REFERENCES}

(1) Squarer, D., Sisk, F. J., Veyo, S. E., 1976. Conceptual Design of a Better Heat Pump Compressor for Northern Climates. International Compressor Engineering Conference at Purdue University, West Lafayette, IN, USA.

(2) Possamai FC, Todescat ML, 2004, A review of household compressor energy performance, Proc. 17th Int. Compressor Engineering Conference at Purdue, CD-ROM.

(3) Lemmon EL, McLinden MO, Huber ML, 2002, REFPROP 7.0, NIST, USA.

(4) Kremer, R. Fonseca Jr., J. N., Dutra, T., 2011. Theoretical and Experimental Analysis of the Superheating in Heat Pump Compressors. $7^{\text {th }}$ International Conference on Compressors and Their Systems, London.

(5) Horn, J., 1976. Design Considerations for Heat Pumps Compressors. International Compressor Engineering Conference at Purdue University, West Lafayette, IN, USA.

(6) Gosney WB, 1982, Principles of Refrigeration, Cambridge University Press.

(7) Giuffrida, G., 1984. High Efficiency Compressor Condenser in a Single Hermetic Component for Heat Pumps. International Compressor Engineering Conference at Purdue University, West Lafayette, IN, USA.

(8) Klein, S. A., 2010. Engineering Equation Solver.

(9) Dutra, T., 2008. Experimental Investigation of the Heat Transfer in Reciprocating Compressors Adopted for Household Refrigeration. M.Sc. Thesis, PPGEM, Federal University of Santa Catarina.

\section{ACKNOWLEDGEMENT}

The authors thank Embraco for support. 